\title{
Melatonin attenuates detrimental effects of diabetes on the niche of mouse spermatogonial stem cells by maintaining Leydig cells
}

\author{
Zhaoyu Du', Shuanshuan Xu', Shuxian Hu', Hong Yang ${ }^{1}$, Zhe Zhou', Kuldip Sidhu², Yiliang Miao ${ }^{3}$, Zhonghua Liu',
} Wei Shen ${ }^{5}$, Russel J. Reiter ${ }^{6}$, Jinlian Hua ${ }^{1}$ and Sha Peng ${ }^{1}$

\begin{abstract}
Diabetes mellitus affects a large number of men of reproductive age and it usually leads to serious reproductive disorders. However, the underlying mechanisms and specific therapies still remain largely unknown. We observed Leydig cell loss in the testes of diabetic mice. Continuous high glycemic status of testes stimulated expression of Caspase12, Grp78, and Chop, the three ERS response factors; this might induce cell cycle arrest and apoptosis of Leydig cells in response to ERS. In these diabetic mouse models, melatonin alleviated apoptosis of testicular stromal cell induced by ERS, and promoted SSCs self-renewal by recovering Leydig cells secretion of CSF1 after 8 weeks of treatment. To explore the relationship between CSF-1 and ERS in Leydig cells, we treated Leydig tumor cell line with an activator Tuniamycin and an inhibitor 4-Phenylbutyrate of ERS. Our data showed that the CSF-1 expression in mouse Leydig cell lines decreased six-fold while reversely increasing five-fold in the 4-Phenylbutyrate-treated group. Thus, melatonin likely alleviates the loss of Leydig cells in diabetic testes and provides a healthier niche for SSCs to selfrenew and continually provide healthy sperm for male fertility.
\end{abstract}

\section{Introduction}

Diabetes mellitus (DM) is a major cause of large-scale morbidity and mortality ${ }^{1}$. It is a syndrome that adversely affects all physiological systems ${ }^{2}$ including the deleterious effects on the male reproductive system both in diabetic men and male animals ${ }^{3,4}$.

Male fertility relies on the continuity of spermatogenesis in the testes ${ }^{5}$ and SSCs that undergo self-renewal and differentiation compose the "fountainhead" of spermatogenesis 6 .

\footnotetext{
Correspondence: Jinlian Hua (jinlianhua@nwsuaf.edu.cn) or Sha Peng (pengshacxh@163.com)

${ }^{1}$ College of Veterinary Medicine, Shaanxi Centre of Stem Cells Engineering \& Technology, Northwest A\&F University, Yangling 712100 Shaanxi, China

${ }^{2}$ Centre for Healthy Brain Ageing, UNSW Medicine, Randwick, NSW 2031, Australia

Full list of author information is available at the end of the article.

These authors contributed equally: Zhaoyu Du, Shuanshuan Xu

Edited by A. Stephanou
}

SSCs are the sole germline stem cells, which sustain selfrenewal and division to replenish the population and generate progenitor spermatogonia for differentiation ${ }^{7}$. The fate of SSCs are influenced by a niche microenvironment composed of a growth factor milieu provided by several testicular somatic-supporting cell populations ${ }^{5}$. In mammalian testes, Sertoli cells, which are the major contributors to the SSC niche $^{8,9}$, play a pivotal role in spermatogenesis. Previous study has indicated that Sertoli cell metabolism is influenced by a testosterone deficiency in progressive stages of $\mathrm{DM}^{10}$ and by the glucose homeostasis which is controlled by the combined action of insulin and melatonin ${ }^{11}$. Disturbance of these regulatory factors may explain male infertility induced due to diabetes since spermatogenesis is supported by Sertoli cell growth factors and transcription factors ${ }^{12}$. A disturbance of testosterone synthesis by Leydig cells in

\section{(c) The Author(s) 2018}

(c) (i) Open Access This article is licensed under a Creative Commons Attribution 4.0 International License, which permits use, sharing, adaptation, distribution and reproduction c. in any medium or format, as long as you give appropriate credit to the original author(s) and the source, provide a link to the Creative Commons license, and indicate if changes were made. The images or other third party material in this article are included in the article's Creative Commons license, unless indicated otherwise in a credit line to the material. If material is not included in the article's Creative Commons license and your intended use is not permitted by statutory regulation or exceeds the permitted use, you will need to obtain permission directly from the copyright holder. To view a copy of this license, visit http://creativecommons.org/licenses/by/4.0/. 
testicular interstitial tissue are also disordered in diabetic testis $^{13}$. In the fetal mouse testis, both Sertoli and Leydig cells are required for testosterone synthesis, while the adult Leydig cells synthesize testosterone to maintain male reproductive function ${ }^{14}$. Thus Sertoli and Leydig cells both play crucial roles in the establishment of the niche microenvironment for SSCs. In addition, interstitial Leydig cells express CSF1, which also stimulates the self-renewal of SSCs in mice ${ }^{15}$. Although the impact of diabetes on Sertoli cell metabolism and testosterone synthesis is becoming increasingly clear, its effect on SSCs self-renewal and differentiation supported by Leydig cells are not well known.

ERS occurs when the ER function becomes perturbed by hypoxia and hypoglycemia, and protein misfolding during biosynthesis ${ }^{16}$. Modulation of ERS maintains the balance between survival and death by regulating autophagy and apoptosis under different stressful conditions. ERS is involved in diabetes-induced testicular cell death ${ }^{17,18}$ and spermatogenesis impairment by reducing testosterone production by Leydig cells ${ }^{19}$. Leydig cells, also known as interstitial cells of Leydig, are found adjacent to the seminiferous tubules in the testicle. Leydig cells produce testosterone in the presence of luteinizing hormone (LH). As Leydig cell is an important part of the male reproductive microenvironment, ERS in diabetic testis could be a major factor to the damage of Leydig cells and inhibit the Leydig cells from supporting the spermatogenesis.

Melatonin, is an indole synthesized and secreted by the pineal gland; its concentrations in the blood vary daily and seasonally in mammals ${ }^{20,21}$. Melatonin prevents various ERS-related diseases and restores the cells damage caused by ERS ${ }^{22,23}$. Melatonin also plays a significant role in the regulation of self-renewal and differentiation of various stem cells, including mesenchymal stem cells ${ }^{24}$ and spermatogenic cells ${ }^{25}$. Moreover, melatonin prevents testicular damage caused by environmental toxins and drugs $^{26-28}$ based on its characteristics of lipophilic and hydrophilic free radical scavengers ${ }^{29,30}$. Whether melatonin prevents ERS in the Leydig cells and then protects the self-renewal capacity of SSCs under high glucose conditions is still unknown.

This study is designed to establish hyperglycemia as a major physiological determinant in SSC microenvironment and demonstrates the direct relationship of the regulation of high-glucose-induced ERS with the specification and maintenance of SSCs. We tested the hypothesis as to whether melatonin application is sufficient to rescue diabetic male fertility damage via inhibition of ERS and activation of SSC self-renewal.

\section{Results}

\section{Diabetes caused Leydig cell loss in mouse testes}

Figure 1 describes the schematic for the experimental plan using ICR mice that were treated with STZ and melatonin. The body weight gain (Fig. 2a) did not vary between D2 and DM2 in the short term experimental groups. Both diabetic groups, particularly the melatonin treatment group, from the longer-duration experiment exhibited a slower weight loss. Blood glucose control was not significantly improved by melatonin (Fig. 2b). The testicular weight was not affected by melatonin treatment under healthy and diabetic conditions in short- and longterm experiments (Fig. 2c). In Figures S1A and S1B, 8week diabetes induced mild puffiness and congestion of the testicles. Conversely, this condition was relieved by melatonin. To examine the cause of the damaged tissues, the morphology of the testes was examined at the light microscopic levels. The findings indicated that hyperglycemia resulted in the loss of Leydig cells (white arrows) and SSCs (black arrows) and promoted the thickening of the basement membrane in the seminiferous tubules

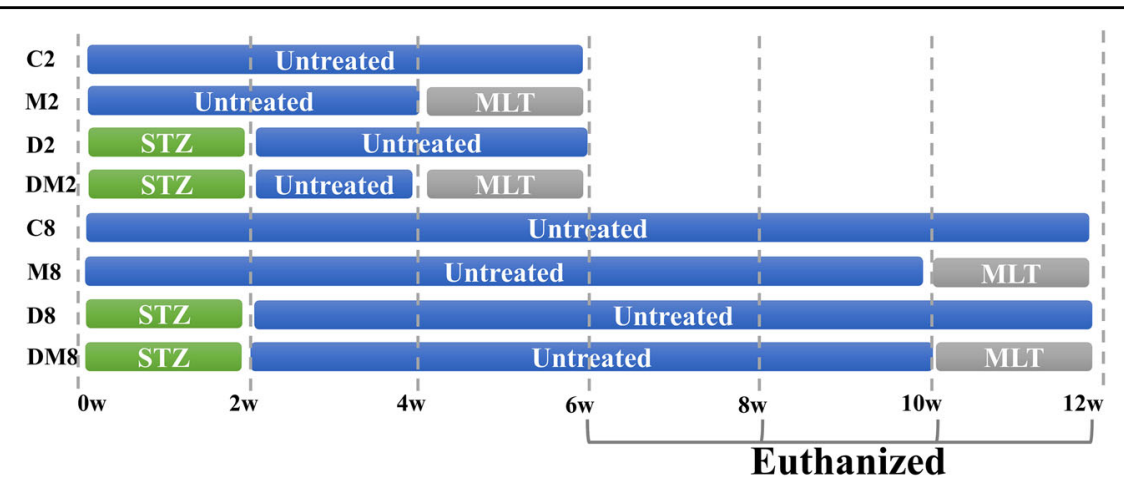

Fig. 1 The schematic of experimental diabetic mouse models prepared using STZ. Melatonin (MLT) was given by gavage daily (10 mg/kg/d) for 2 or 8 weeks. Diabetes was induced by a single dose of streptozotocin (STZ) by intra-peritoneal injection (100 mg/kg) on the first day. C2 and C8: twoweek and eight-week controls, M2 and M8: two-week and eight-week groups treated with melatonin daily during the period, D2 and D8: two-week and eight-week diabetic, DM2 and DM8: two-week and eight-week diabetic treated with melatonin. Euthanasia was performed at the 6th and 12th week. MLT: melatonin 


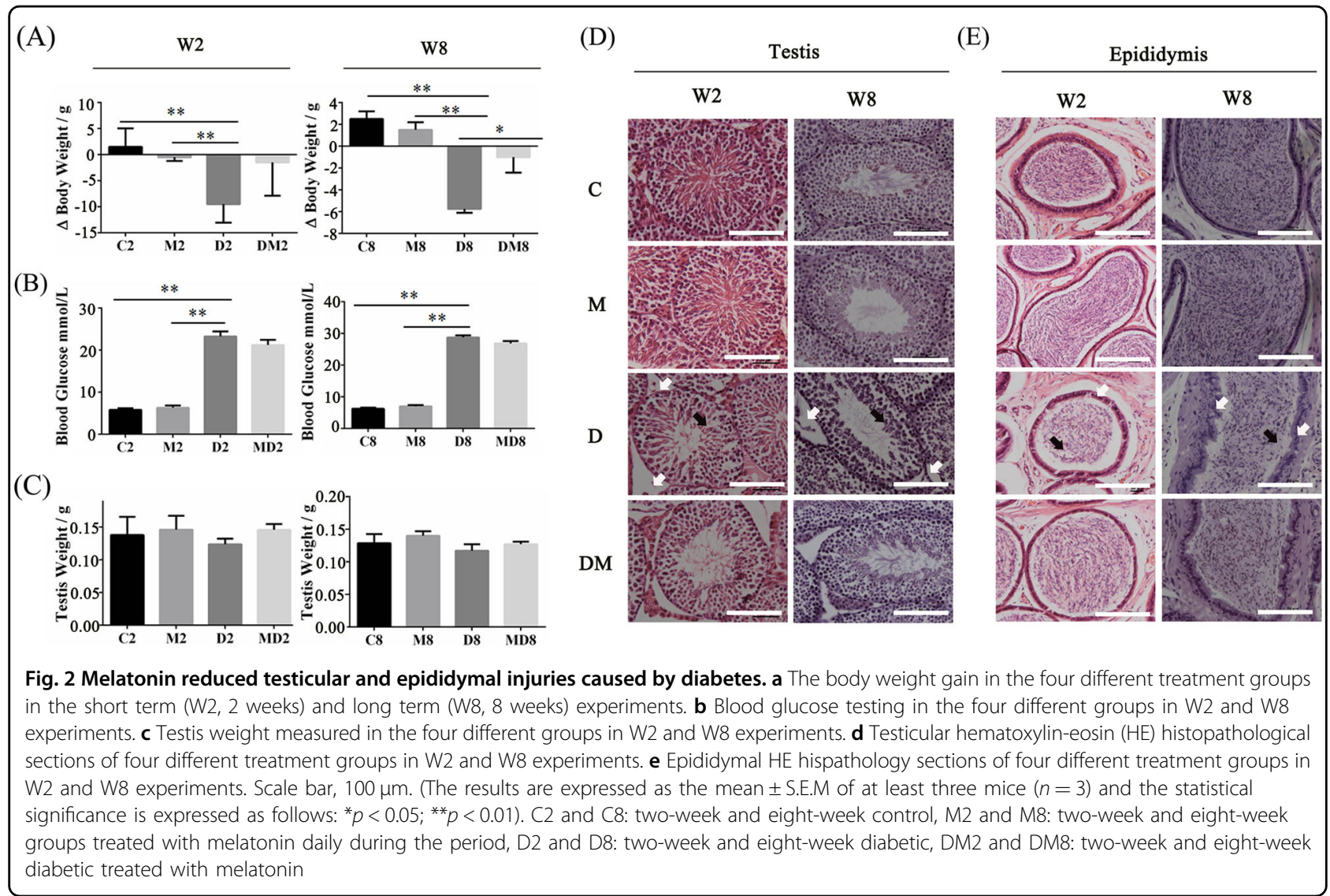

(Fig. 2d) in short term and long term experiments. The sperm density in the epididymis of the diabetic mice was significantly reduced (black arrows), and the integrity of the epididymal duct wall was disrupted (white arrows) when melatonin treatment was not administered (Fig. 2e).

\section{Melatonin improved cell survival in the testis with hyperglycemia by decreasing ERS}

To explore the causes of cell loss, the expression of PCNA was examined; this is a specific markers of cell proliferation. PCNA protein level was significantly lower $(P<0.05)$ in the diabetes group than in the control group (Fig. 3a). The proportion of PCNA-positive cells in the DM group increased in short- and long-term experiments. Anti-apoptosis is regarded as an essential function of melatonin in reproductive cells ${ }^{31}$. Melatonin could substantially reduce the number of apoptotic cells (Fig. 3b and $\mathrm{S} 2 \mathrm{~A}$ ) from $54.4 \%$ to $39.8 \%$ in the 2-week group and from $51.8 \%$ to $37.9 \%$ in the 8 -week group. Different ploidy types of cells were counted by flow cytometry because haploid testicular cells, especially spermatids, were included (Fig. S2B). In short- and long term experiments, the low proportion of the tetraploid cells in the testes of the diabetic mice reached $10.5 \%$ and $12.1 \%$, respectively. This observation implied that cell proliferation declined. The proportion of the haploid cells in 8-week diabetics decreased from $56.7 \%$ to $51.6 \%$, which might be the direct cause of reduced fertility; this proportion recovered to $54.1 \%$ in the DM group (Fig. S2B). In further experiments, sperm with abnormal characteristics, such as unusually large heads, sickle-shaped heads, and curly tails, were found in semen on the epididymis smear obtained from the diabetic mice (Fig. 3c). Moreover, melatonin therapy protected the sperm from damage by diabetes (Fig. 3C).

To investigate how melatonin decreases cell apoptosis in the testes, the gene expression profile was analyzed in the testicular tissue from the mice with and without melatonin therapy. RT-qPCR analysis demonstrated that the expression levels of $p 53$ and caspase 3 in melatonintreated diabetic mice were significantly lower $(P<0.01)$. By comparison, the expression level of $B c l 2$ was higher than that in diabetic mice (Fig. 3d). In Fig. 3e, the Bcl2/ Bax ratio was significantly $(P<0.01)$ enhanced and the p53 and caspase 3 expression levels decreased in melatonin-treated diabetic testes. Cell loss induced by excessive apoptosis occurred in the diabetic mice. Apoptosis is associated with many chronic inflammatory diseases, including diabetes, and ERS is one of the main causes of apoptosis. After a 2-week melatonin treatment, 
(A)
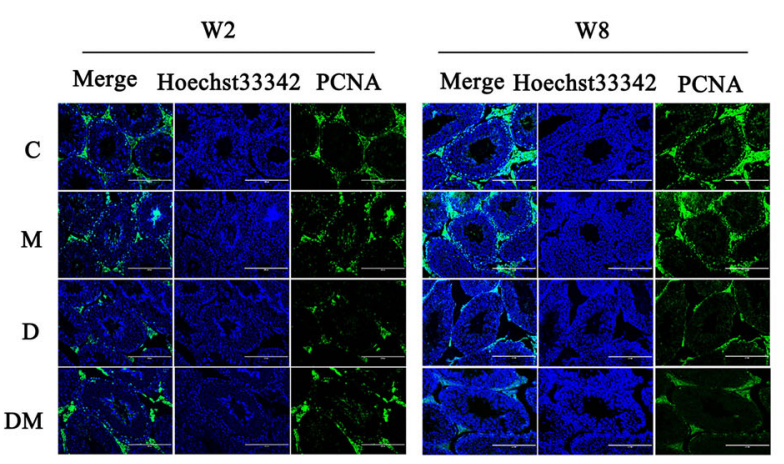

(C)

C8

M8

D8

DM8

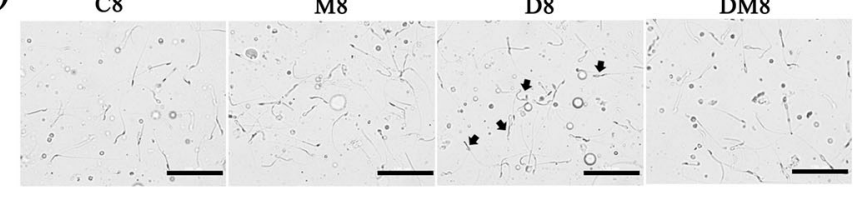

(E)
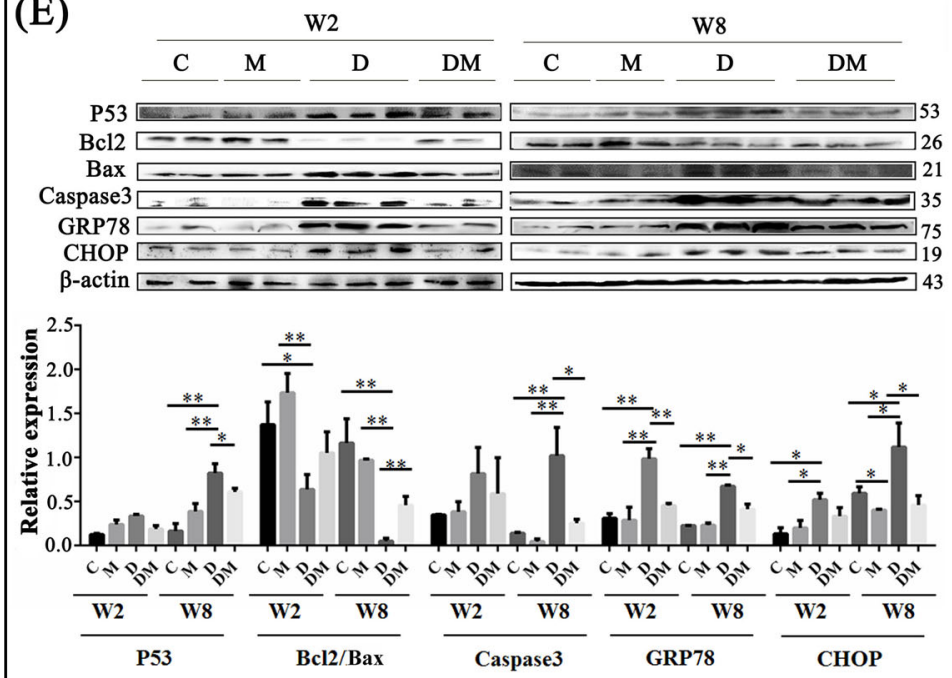

(B)

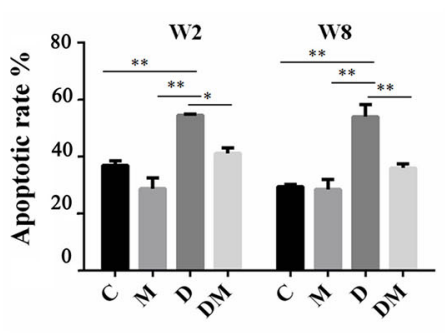

(D)
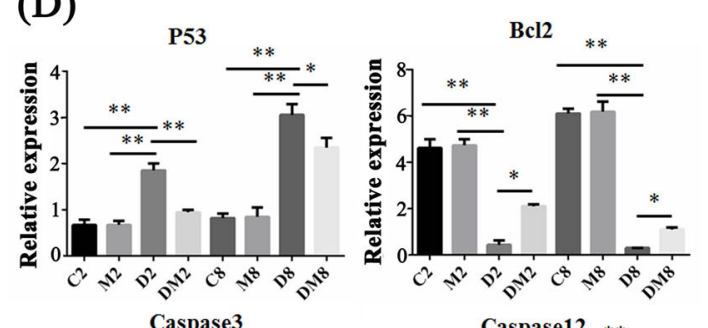

Caspase12 **
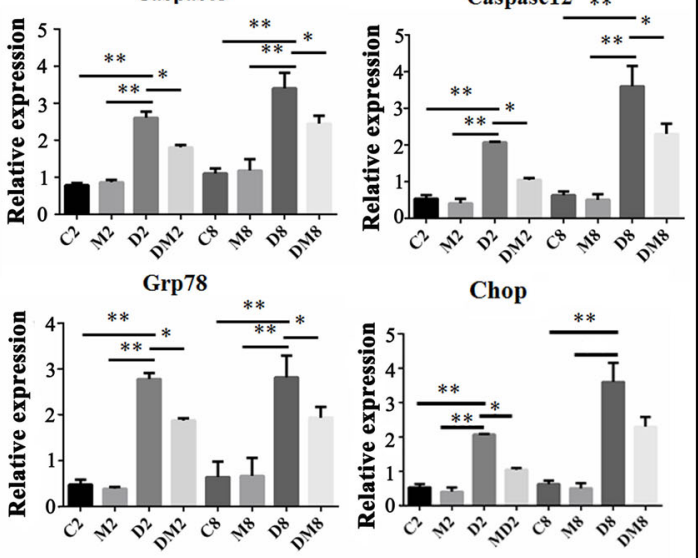

Chop

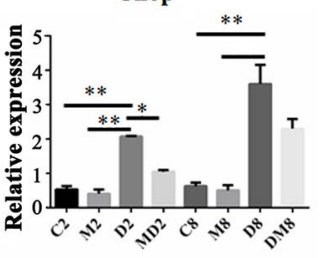

Fig. 3 Effect of melatonin on the proliferation, cell survival, and spermatogenic function of testicular tissue. a PCNA expression in testes of four different treatment groups in short term (W2, 2 weeks) and long term (W8, 8 weeks) experiments. Scale bar, 200 um. b Cell apoptosis rate was determined by flow cytometry (FCM). c Epididymal semen smears of four different groups in W8 experiments. Scale bar, $100 \mu \mathrm{m}$. Black arrows in D8 show the abnormal characteristics. d RT-qPCR analysis of apoptosis-related genes (P53, BCI2, Caspase 3 and Caspase 12) and endoplasmic reticulum stress-related genes (Grp78 and Chop) in testicular cells suspensions of four different groups in W2 and W8 experiments. e Western blot analysis of apoptosis-related genes in testicular cell suspensions of four different groups in W2 and W8 experiments. The histograms show quantitative results of Image J (V1.48d) gradation analysis for the western blot experiments. (The results are expressed as the mean \pm S.E.M of at least three mice $(n=3)$ and the statistical significance is expressed as follows: $\left.{ }^{*} p<0.05 ;{ }^{* *} p<0.01\right)$. C2 and C8: two-week and eight-week control; M2 and M8: two-week and eight-week groups treated with melatonin (MLT) daily during the period; D2 and D8: two-week and eight-week diabetic; DM2 and DM8: two-week and eight-week diabetic treated with MLT

the mRNA expression levels of the detected ERS markers, including Caspase12, Grp78, and Chop, were lower than those in the diabetic mice (Fig. 3d). In Fig. 3f, g, the protein expression levels of $\mathrm{CHOP}$ and Grp78 were reduced. These data imply that hyperglycemia caused an imbalance of homeostasis in the ER and thus stimulated ERS. ERS exacerbation might aggravate testicular injury in diabetic animal models.

\section{Melatonin protected Leydig cells under high glucose condition}

In Figs. $2 \mathrm{~d}$ and 3a, Leydig cells experienced the most severe loss and the most evident proliferative inhibition in diabetic mouse testes. First, the glucose sensitivity of different types of testicular cells was compared. Two mouse SSC lines (GC-1 and C18-4) and one Leydig tumor cell line (MLTC-1) were treated with $20 \mathrm{mM}$ glucose. 


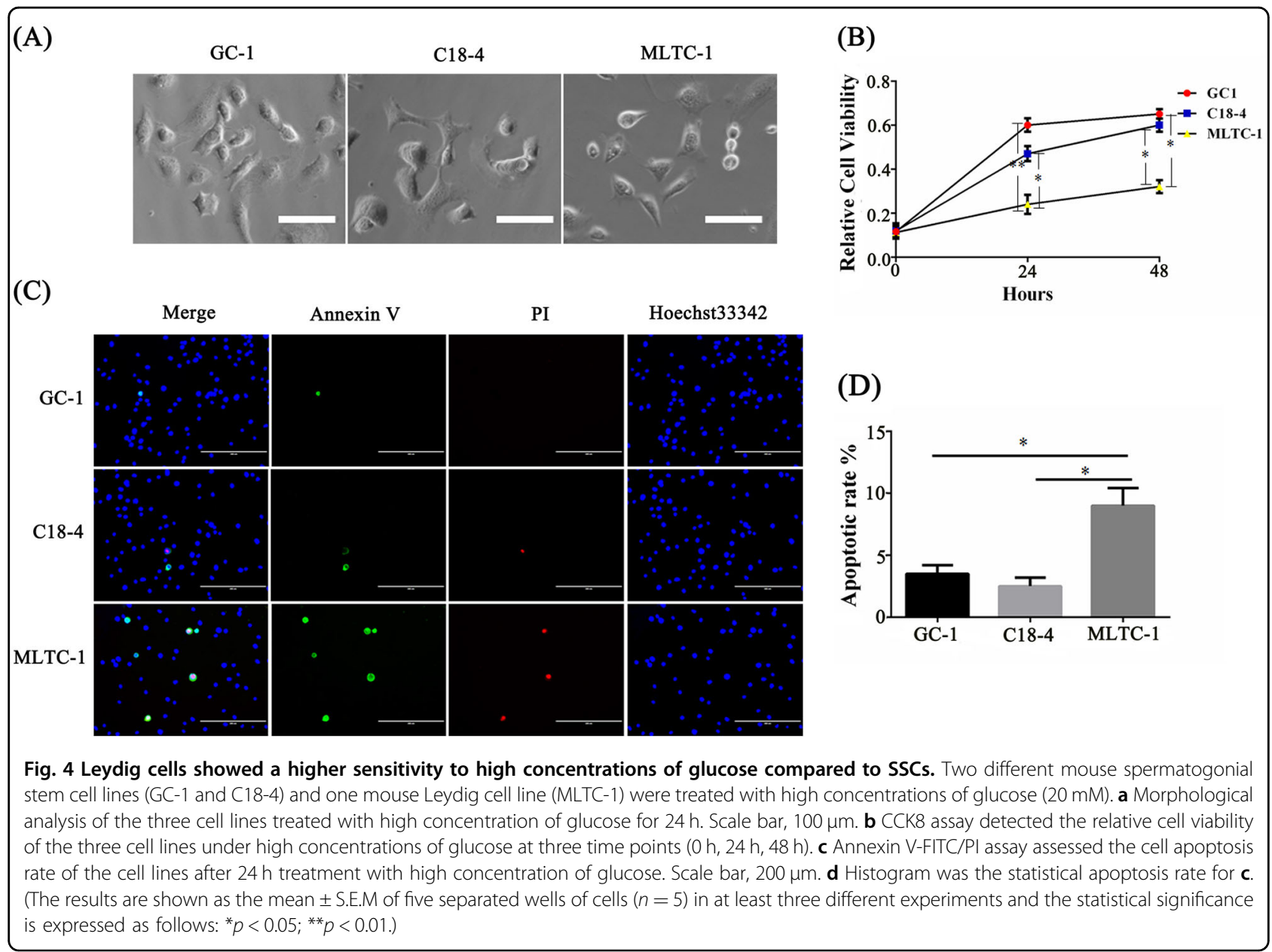

After $24 \mathrm{~h}$ of incubation with high glucose, the morphological characteristics of the MLTC-1 cells were significantly changed; that is, they shrank and became round (Fig. 4a). The viability of the MLTC-1 cell decreased to a greater extent than that of two other SSC lines (Fig. 4b). The proportion of apoptotic MLTC-1 cells reached 9\% (Fig. 4c, d), which was significantly higher than that of the two other groups.

MLTC-1 cells were treated with $20 \mathrm{mM}$ glucose and 1 $\mu \mathrm{M}$ Melatonin. After $24 \mathrm{~h}$, significant differences were observed. In particular, compared with the cells in the control group $(C)$ and the melatonin group $(M)$, the cells in the high-glucose group (G) shrank and became round, exhibited a loose arrangement in a monolayer, lost adhesion properties, and floated on the medium. The viability of the cells under high glucose in combination with melatonin treatment (GM) was recovered (Fig. 5a). BrdU positive incidence of MLTC-1 recovered from 7.6\% in G groups to $19 \%$ in GM groups (Fig. 5b-d). Meanwhile, the excessive apoptosis decreased from $43 \%$ in $\mathrm{G}$ groups to $23 \%$ in GM groups (Fig. $5 \mathrm{c}-\mathrm{e}$ ). The apoptosis assay also confirmed that melatonin lowered the high apoptotic rate caused by high glucose (Fig. $5 \mathrm{f}$ and S3A). To investigate how high glucose inhibited MLTC-1 proliferation, the cell cycle was analyzed by means of flow cytometry. In Fig. $5 \mathrm{~h}$ and S3B, high glucose treatment contributed to the $\mathrm{G} 2 / \mathrm{M}$ phase arrest of MLTC-1, which was relieved by melatonin treatment.

Diabetes increased ERS in whole testicular tissues, and MLTC-1 cells were highly sensitive and apoptotic under the high glucose condition, while the SSCs cell lines were less sensitive to high glucose. These findings suggested that high glucose induced excessive ERS in Leydig cells, which was alleviated by MLT. RT-qPCR and Western blot results indicated that ERS-related genes, including Grp78, Chop, and Caspase12, were increased under highglucose condition in the MLTC-1 cells. High glucoseinduced ERS triggered cell apoptosis, as marked by P53, $B c l 2$, caspase 3 and $P 21$ (Fig. 5g). Consistently, the protein expression levels of P53, Caspase 3 and $\mathrm{CHOP}$ were elevated, whereas the protein expression level of $\mathrm{Bcl} 2 / \mathrm{Bax}$ dropped (Fig. 5i, j). 


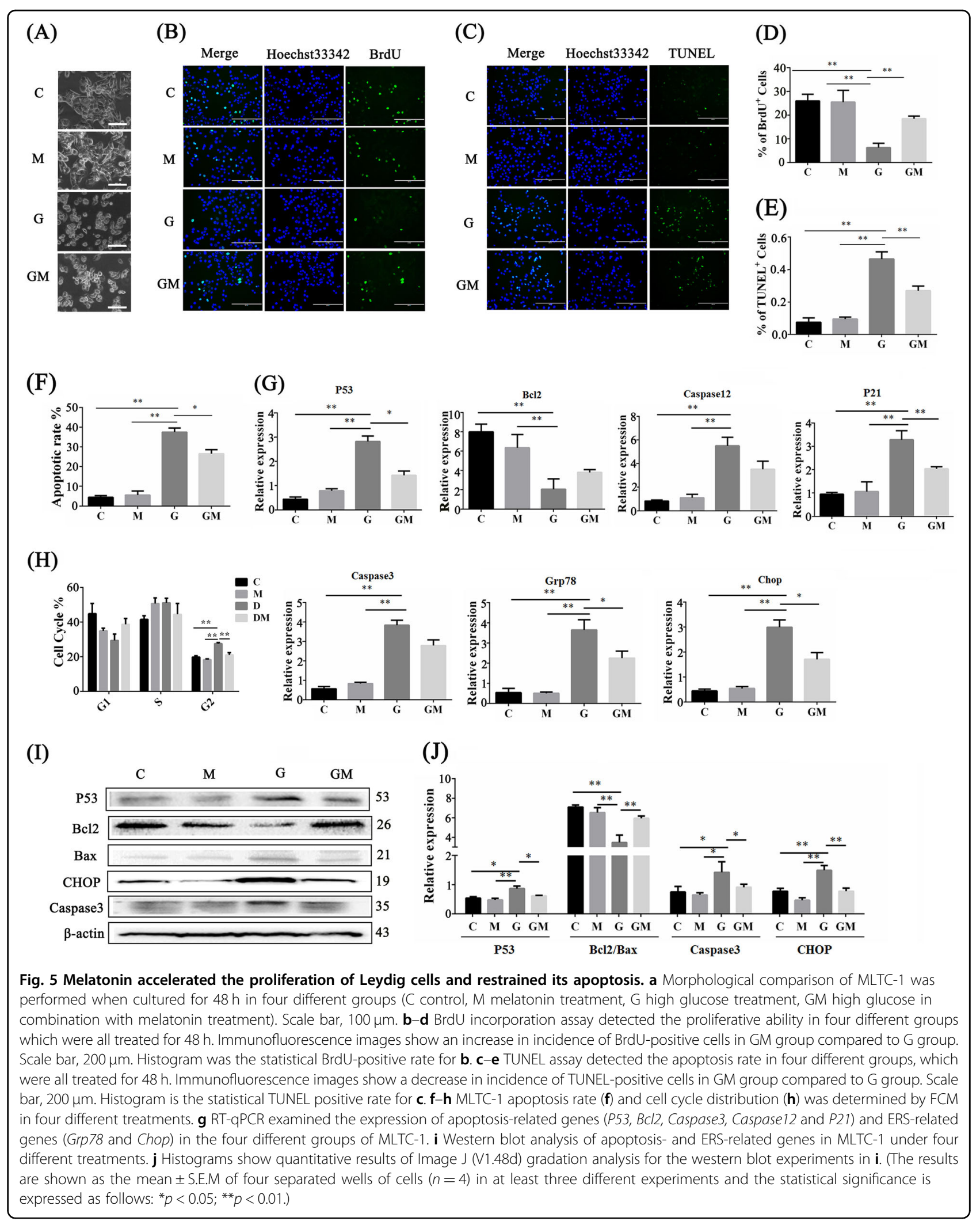




\section{ERS in Leydig cells inhibited SSC self-renewal capacity}

On the basis of the findings, it was hypothesized that the increased ERS levels supported by a high-glucose environment promoted apoptosis of Leydig cells and contributed to the progression of male reproductive injury. To intervene in ERS caused by a high-glucose environment in Leydig cells, the MLTC-1 cells are treated with Tm and 4PBA, which, respectively, caused and inhibited excessive ERS. It was confirmed that high glucose and Tm triggered excessive ERS, and the cell activity remarkably decreased in the Tm-treated group; and this was effectively mitigated by melatonin and 4PBA (Figs S4A and S4B). Mitomycin C was then used to treat MLTC-1 cells pretreated by 4PBA in combination with $\mathrm{Tm}$ to produce the feeder layers for SSCs. When morphologically growing on the feeder pretreated with Tm, SSCs were unable to proliferate to form clones, while SSCs growing on the feeder layer treated with melatonin and 4PBA showed a significantly improved colony-formation ability (Fig. 6a). To determine the ability of SSC proliferation, SSCs were marked with PLZF antibody and a BrdU incorporation assay was performed. The results suggested that the pretreated feeder layer with Tm decreased the positive rate of BrdU SSCs (Fig. 6b). In the cells pretreated with Tm and 4PBA, the rate of the BrdU-labeled cells measured was found higher than that in the Tm-treated groups. These SSCs then grew rapidly into colonies as in the control group. Then, SSCs from different feeder layers were harvested and the markers of self-renewal and differentiation were estimated. In Fig. 6c, the mRNA expression levels of Gfro1, Lin28a, Etv5, Plzf, C-Myc, and PCNA were sharply reduced in the SSCs growing on the feeders treated with Tm. In contrast, the expression levels of these genes increased when the cells grew on the feeder layers treated with $\mathrm{Tm}$ and 4PBA. Consistent with the mRNA expression pattern, the GFR $\alpha 1$, PLZF, C-MYC and PCNA protein expression levels were downregulated in the SSCs growing on the feeder layers under ERS (Fig. 6d, e). However, the expression levels of meiosis inducers, such as STRA8 and DAZL, did not significantly change (Fig. 6c-e).

\section{Melatonin protected CSF1 function against high glucose suppression in testis}

Micro-environmental conditions called a niche are essential to SSC self-renewal and spermatogenesis. Considering the damaged Leydig cells, secretory functions of Leydig cells, and the important roles of CSF1 in SSC selfrenewal, it was assumed that CSF1 played the most important role in melatonin maintenance of SSC selfrenewal under high glucose conditions.

The mRNA and protein expression levels of CSF1 in mouse testes were using immunofluorescent staining, RT-qPCR, and Western blot. The CSF1 protein levels in the diabetic mice were significantly lower than those in the control mice (Fig. 7a). The proportion of CSF1positive cells increased in the DM group in short- and long-term experiments. Compared with that in the normal group, the serum CSF1 was increased significantly in the melatonin-treated group (Fig. 7b). In Fig. 7c, the mRNA expression level of CSF1 was sharply reduced in the testicular cells of the mice with diabetes in short- and long-term experiments. By comparison, the expression of these genes was elevated in the mice treated with melatonin. Consistent with the mRNA expression pattern, the CSF1 protein expression was downregulated in the testicular cells of the mice with diabetes and restored significantly in the long term melatonin treatment groups $(P<0.01)$ (Fig. $7 \mathrm{~d})$. These results reveal that some of Leydig cells lost their CSF1 synthesis and secretory functions in diabetes in long- or short-term experiments.

\section{ERS suppressed CSF1 expression in Leydig cells}

To determine whether ERS downregulated CSF1, the expression of CSF1 was detected in MLTC-1 cells treated with 4PBA and Tm. In Fig. 8a, excessive Tm-induced ERS sharply decreased the proportion of CSF1-positive cells, but this parameter was improved by treating the cells with Tm in combination with 4PBA. Similar results were confirmed using ELISA (Fig. 8b). To further verify these findings, CSF1 expression was also determined through RT-qPCR and Western blot. Consistent with the pattern illustrated in Fig. 8a, b, the mRNA and protein expression levels of CSF1 were downregulated in the MLTC-1 cells exposed to excessive ERS, while restoring ERS (Tm combined with 4PBA) improved CSF1 expression (Fig. 8c, d). Moreover, the CSF1 receptor (CSF1R) was also detected. In Fig. S5, the positive rate of CSF1R in SSCs incubated on the feeder layer under ERS was not significantly different from that of the control group.

\section{Discussion}

DM accounts for the highest incidence among chronic metabolic diseases which pose a risk to human health, and induces major damage to many systems and organs ${ }^{32}$. The abnormal glucose metabolism plays an important role in the molecular lesions and organ pathology. Especially, Type 2 DM (T2DM), has become increasingly prevalent among children/adolescents and adults of reproductive age and results in high incidence of male infertility which emerges as a pressing health issue $\mathrm{e}^{33,34}$. Studies have reported a link between DM and male infertility. DM causes histopathology damage to testes ${ }^{35}$ and contributes to male infertility by triggering abnormal spermatogenesis, which results in impaired sperm parameters ${ }^{36}$.

The high blood glucose caused by DM changes glucose metabolism in the testis. Leydig cells and SSCs are destroyed under the high glucose conditions ${ }^{35}$. We used 


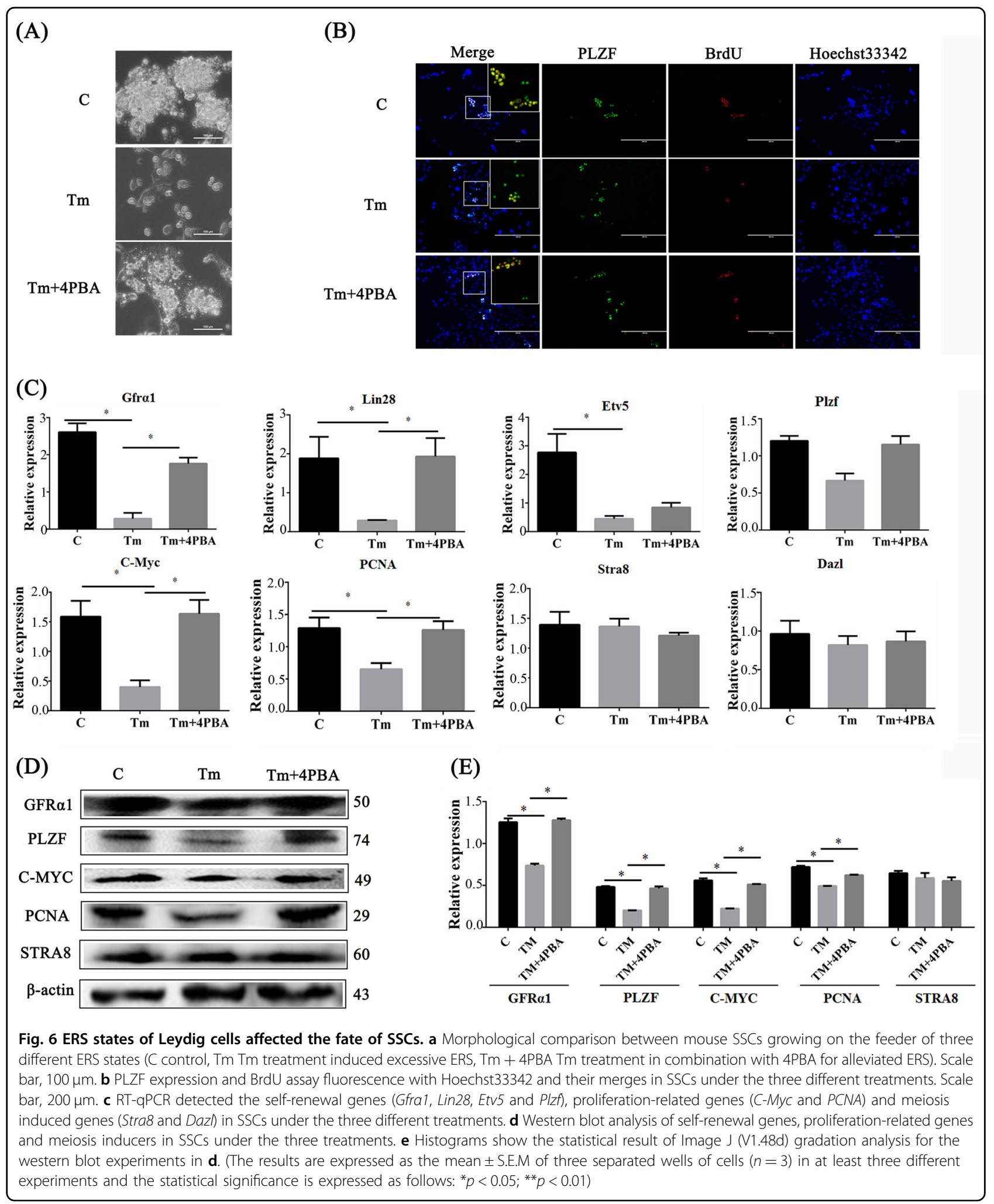

STZ-induced diabetic mice to examine diabetes-induced male infertility ${ }^{20}$, and explore the mechanism of infertility resulted from $\mathrm{T} 2 \mathrm{DM}$; the data demonstrated that hyperglycemia in STZ-induced diabetic mice was accompanied by the loss of Leydig cells and SSCs. Apoptosis is associated with diabetes, and ERS is one of 


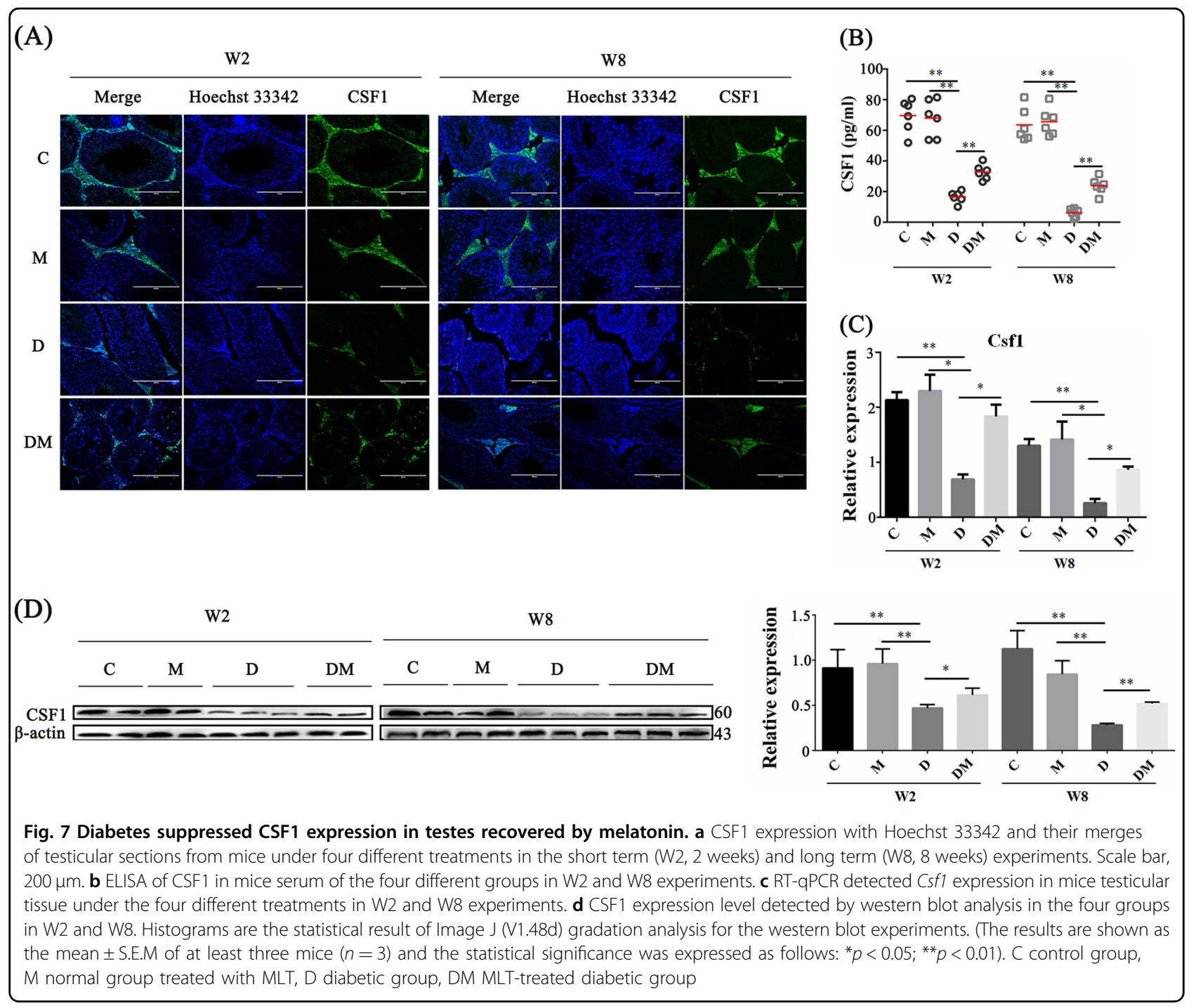

the main causes of apoptosis. The apoptosis activated in the STZ-induced diabetic mice testis and epididymis was mediated by $\mathrm{ERS}^{37}$. High-glucose-induced ERS is also closely linked to various aspects of cell dysfunctions in patients with diabetes ${ }^{38,39}$. In Akita mice, ERS directly induces $\beta$-cell death and dysfunction ${ }^{40-43}$. ERS adversely affects the insulin-secreting function of $\beta$-cells in the pancreas, and the insulin deficiency consequently induces hyperglycemia ${ }^{44}$. One report documented that the ERS in the Drosophila male accessory gland results in infertility ${ }^{45}$. Hence, ERS-induced apoptosis in testis is an important consideration for infertility resulted from diabetes. In our study, we found that hyperglycemia augmented ERS and apoptosis of Leydig cells, and disturbed the homeostasis of SSCs niches in STZ-induced diabetic mice. Thus, it was likely that the ERS induced by hyperglycemia caused the loss of both the Leydig cell and $\mathrm{SSCs}^{46}$.
Melatonin, a compound secreted by the pineal gland, functions as an antioxidant and free radical scavenger $^{47-51}$, and has a widespread clinical application ${ }^{52,53}$. In addition to oxidative stress inhibition, ERS is slightly decreased by melatonin after a prolonged high glucose treatment in pancreatic $\beta$-cells ${ }^{39,54,55}$. Melatonin directly and indirectly ameliorates ERS in multi-pathologies ${ }^{56}$. Melatonin directly mediates insulin biosynthesis in INS$1 \mathrm{E}$ cells under induced ERS ${ }^{57}$. Melatonin also functions as an inhibitor of lipopolysaccharide-mediated placental ERS in mice ${ }^{58}$ and significantly attenuates Cd-induced ERS in mouse testes ${ }^{59}$. Melatonin also has antiinflammatory effects via ERS in acute pancreatitis ${ }^{60}$. Thus, melatonin may repair the adverse effects of hyperglycemia on Leydig cells and SSCs by inhibiting ERS. We found that melatonin reduced the apoptosis rate of cells in the testes by inhibiting expression of Grp78, CHOP, and Caspase12 which were related to ERS 


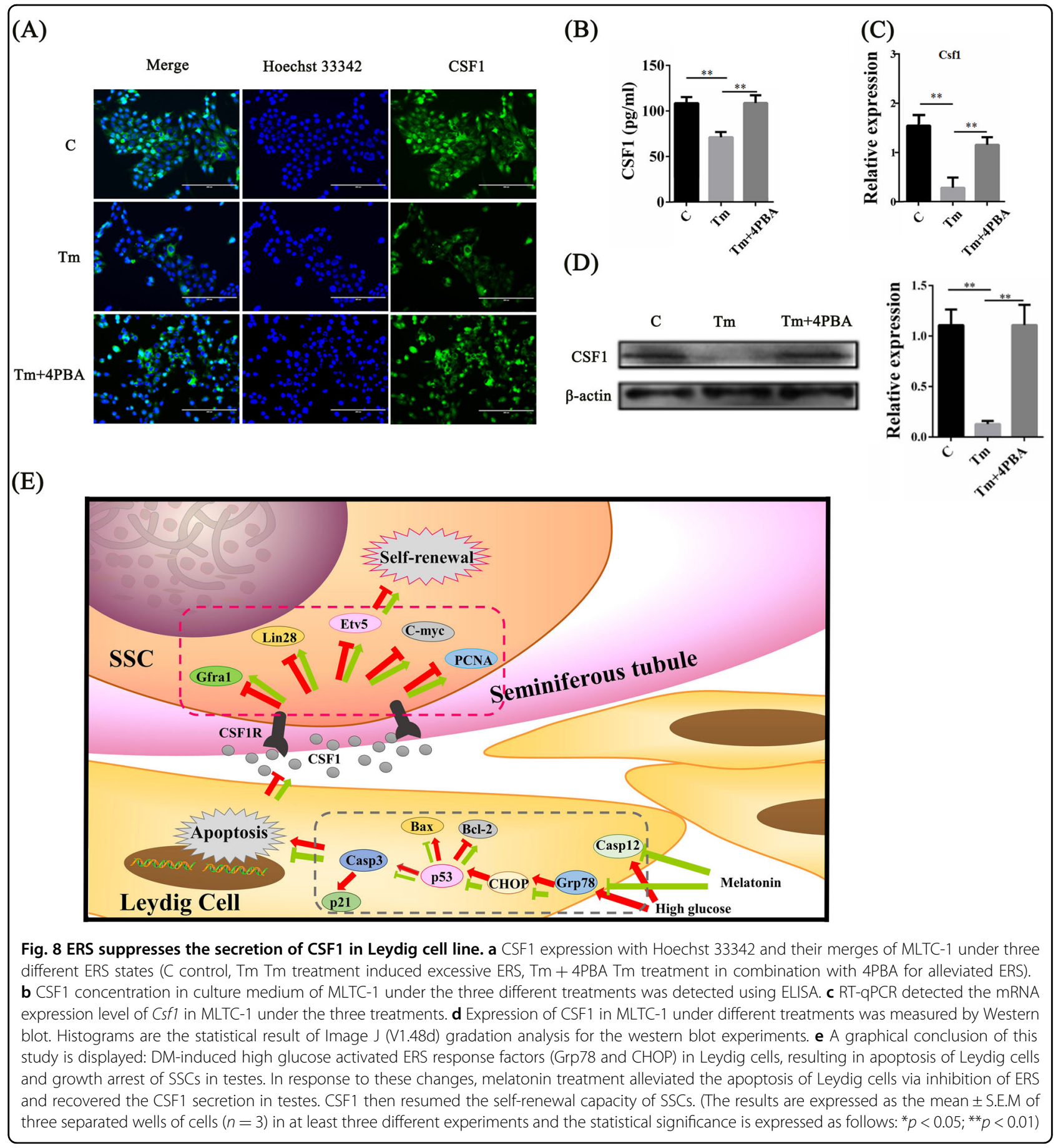

in STZ-induced diabetic mice. Moreover, the in vitro cell culture assay demonstrated that MLTC-1 was more sensitive to high glucose than SSC lines and thus they underwent apoptosis. The expression levels of ERSrelated genes, including Grp78, Chop, and Caspase12, increased at high glucose levels in MLTC-1 cells. Thus, high blood glucose seems to promote ERS in Leydig cells. Subsequently, the dysfunction of Leydig cells might impact the status of SSCs. When MLTC-1 cells were treated with melatonin, both the ERS and apoptosis were alleviated in high glucose environment. Flow cytometry analysis further showed that melatonin decreased the high apoptotic rate of testicular cells. These results indicated that ERS supported by a high glucose environment induces apoptosis of Leydig cells and contributes to the progression of the injury to the male reproductive system. 
In combination with the inhibitor and activator of ERS, i.e., 4PBA and Tm, treated MLTC-1 when co-cultured with SSCs, the self-renewal and proliferation of SSCs were closely related to the ERS status of MLTC-1. These findings indicate that melatonin overcomes the hyperglycemia-induced ERS, while the ERS promotes apoptosis of Leydig cells in STZ-induced diabetic mice. Thus melatonin improved the male reproductive physiology.

Testes produce sperm throughout the male reproductive lifespan by balancing the self-renewal and differentiation of SSCs ${ }^{61}$. The regeneration and differentiation of SSCs were supported by the Leydig cells ${ }^{62}$. Leydig cells secrete essential hormones and cytokines to maintain male reproductive functions. Testosterone is the main resource of androgens in the testis, which is produced by Leydig cells but regulated mainly by cytokine secreted by Sertoli cells. Melatonin acts as a local modulator of the endocrine activity in Leydig cells, and melatonin is a key player in the regulation of steroidogenesis $^{63}$. We hypothesize that MLT improved the cytokines secretion processes that were initially destroyed by ERS in Leydig cells, and then repaired the function of SSCs. Cytokines, such as CSF1, are expressed by macrophages on the surface of seminiferous tubules, near the SSC niche enriched by undifferentiated spermatogonia $^{61}$. CSF1 is an extrinsic stimulator of SSC self-renewal and Leydig cells are contributors to the testicular stem cell niche in mammals ${ }^{15}$. In the current study, the inhibition of CSF1 expression and secretion caused by ERS in testes and MLTC-1 were both improved by melatonin. However, no changes of CSF1R level in SSCs were noted. Thus, it was inferred that melatonin increased the CSF1 secretion of Leydig cells and promoted the selfrenewal of SSCs. CHOP-induced apoptosis in ERS has been implicated in diabetes ${ }^{64}$; we also found that high glucose treatment upregulated the expression of $\mathrm{CHOP}$ and Grp78 and activated apoptosis in Leydig cells. The loss of Leydig cells resulted in a deficiency of CSF1 secretion in the SSC niche, leading to the SSCs self-renewal capacity damage. This study is the first to demonstrate that CSF1 is implicated in the role of melatonin maintaining SSC self-renewal under high glucose conditions.

In conclusion, melatonin reduced Leydig cell apoptosis induced by ERS and increased the secretion of the cytokine, CSF1, which improved the reduced spermatogenesis caused by diabetes. Our studies suggest a novel therapy for hyperglycemia-induced male infertility from the standpoint of the source of mature sperm, which are promoted by melatonin therapy. Further study is needed to determine whether the SSC selfrenewal capacity is directly or indirectly promoted by the melatonin therapy.

\section{Experimental procedures}

\section{Animals and animal experimental protocol}

Figure 1 provides the schematic design of the experimental protocols. The five-week-old ICR male mice were divided into four groups. Group D mice served as STZ diabetic group. They were fed with normal mouse chow and received a single intraperitoneal injection of STZ diluted in citric acid buffer ( $100 \mathrm{mg} / \mathrm{kg}$ body weight) on day 1 . The effects on sperm cell developmental physiological and biochemical properties were tested after 2 or 8 weeks of STZ injection. Group M mice served as melatonin-treated group. They were fed with normal mouse chow and treated with a daily single dose of melatonin $(10 \mathrm{mg} / \mathrm{kg} / \mathrm{d})$ diluted in saline through gavage ${ }^{65-67}$. The disposal time points are shown in Fig. 1. Group DM mice served as STZ-MLT-treated group. They were fed normal chow and injected intraperitoneally with single dose of STZ as in group D mice and administered also with a daily single dose of melatonin $10 \mathrm{mg} / \mathrm{kg}$ through gavage. Group $\mathrm{C}$ mice (control group) were fed with normal mouse chow and given a daily single dose of saline as the solvent administered to the MLT-treated group via gavage. Each group consisted of 4-8 mice.

\section{Isolation of germ cells and the experimental protocol}

Mouse SSCs were isolated from testes at Day 6 postnatal mice. The tunica albuginea was separated under the stereomicroscope and testis was digested with collagenase IV (Invitrogen, Carlsbad, CA, USA) for $15 \mathrm{~min}$ and pipetted repeatedly for $5 \mathrm{~min}$ and then centrifuged at $1200 \mathrm{rpm}$. The seminiferous tubules were isolated from mouse testes using a small surgical scissors. The male germ cells were separated using a second enzymatic digestion with $4 \mathrm{mg} / \mathrm{ml}$ collagenase IV (Invitrogen), $2 \mathrm{mg} / \mathrm{ml}$ trypsin (Invitrogen) and $1 \mu \mathrm{g} / \mathrm{ml}$ DNase I (Invitrogen). The cell suspension was incubated for $1 \mathrm{~h}$ at $37^{\circ} \mathrm{C}$ in gelatin-coated dish, $1 \mathrm{~h}$ at $37^{\circ} \mathrm{C}$ and then in laminin-coated dish to eliminate residual adherent Sertoli cells (differential plating). Then the SSCs were collected by centrifugation at $1400 \mathrm{rpm}$ for $5 \mathrm{~min}$. The primary cells were seeded as $1 \times 10^{5}$ cells $/ \mathrm{ml}$ onto mitotically inactivated mouse embryonic fibroblast (MEF) cell feeders $(5 \times$ $10^{4}$ cells $/ \mathrm{cm}^{2}$ ). Then the cells were maintained at $37^{\circ} \mathrm{C}$ in a humidified $5 \% \mathrm{CO}_{2}, 95 \%$ air atmosphere. After 1-2 weeks, large multicellular ( $>100$ cells) colonies that formed on the dish were sequentially passaged every 3 days. The medium was changed every two days and cells were subcultured using TrypLE (Invitrogen) at a 1:2-3 dilution. SSCs were cultured in $\alpha$-MEM medium, supplemented with 10\% FBS (Hyclone, Logan, UT, USA), 0.1 $\mathrm{mM}$ 2-mercaptoethanol (Invitrogen), $4 \mathrm{mM}$ glutamine (Invitrogen), 1\% non-essential amino acids (Invitrogen), $10 \mathrm{ng} / \mathrm{ml}$ GDNF (Peprotech, Rocky Hill, NJ, USA), $20 \mathrm{ng} /$ $\mathrm{ml}$ EGF (Millipore, Temecula, CA, USA), 20 ng/ml bFGF 
(Millipore) and $1000 \mathrm{U} / \mathrm{ml}$ LIF (Millipore) and incubated at $37^{\circ} \mathrm{C}$ in $5 \% \mathrm{CO}_{2}$ balance air atmosphere.

C18-4 cells (from Mus musculus, a spermatogonial stem cell line) were cultured with Dulbecco's Modified Eagle's Medium/Nutrient Mixture F12 (DMEM/F12, Gibco, Grand Island, NY, USA) supplemented with 10\% FBS (Hyclone), $2 \mathrm{mM}$ L-glutamine (Invitrogen), and $100 \mathrm{U} / \mathrm{ml}$ penicillin and streptomycin (Invitrogen) ${ }^{68}$. GC1 (Mus musculus, BALB/c, established, ATCC number: CRL$2053^{\mathrm{TM}}$ ) cells were cultured with Dulbecco's Modified Eagle's Medium (DMEM, Gibco) supplemented with $10 \%$ FBS (Gibco), $2 \mathrm{mM}$ L-glutamine (Invitrogen), and $100 \mathrm{U} / \mathrm{ml}$ penicillin and streptomycin (Invitrogen) ${ }^{69}$. MLTC-1 cells (Mus musculus, C57BL/6, established cell line, ATCC number: CRL-2065 ${ }^{\mathrm{TM}}$ ) were cultured with 1640 Medium (RPMI-1640, Gibco) supplemented with 10\% FBS (Gibco), $2 \mathrm{mM}$ L-glutamine (Invitrogen), and $100 \mathrm{U} / \mathrm{ml}$ penicillin and streptomycin (Invitrogen). The cells were passaged every 3-4 days and maintained at $37^{\circ} \mathrm{C}$ in a humidified $5 \% \mathrm{CO}_{2}$ incubator. The cells were dissociated by $0.25 \%$ trypsin-EDTA (Invitrogen) and reseeded into multi-well plates for the subsequent experiment, the medium was changed every 2 days. The cells were cultured $24 \mathrm{~h}$ prior to experiments at the cell density of $5 \times 10^{4}$ cells $/ \mathrm{cm}^{2}$ approximately.

Melatonin was dissolved in DMSO physiological saline to $10^{-3} \mathrm{M}$. Tunicamycin (Tm) (Sigma, St. Louis, MO, USA) and 4-phenyl butyric acid (4PBA) (Sigma) were dissolved in DMSO and prepared at $10 \mu \mathrm{M}$ and $1 \mathrm{M}$ concentrations, respectively.

\section{Immunofluorescence staining}

The cells cultured in 48-well plate were fixed with $4 \%$ formaldehyde for $10 \mathrm{~min}$ at room temperature (RT) and were washed with $\mathrm{PBS} \times 3,5 \mathrm{~min}$ each time. The cells were permeabilized by $0.1 \%$ Triton X-100 for $10 \mathrm{~min}$ at $\mathrm{RT}$ and were blocked for minimum 30 min with $1 \% \mathrm{BSA}$ at RT. Then the cells were incubated with primary antibodies specific against PCNA (1:100, mouse IgG, Sangon, Shanghai, PRC), PLZF (1:300, mouse IgG, Abcam, Cambridge, UK), CSF1 (1:100, rabbit IgG, Sangon), CSF1r (1:100, mouse IgG, Sangon), respectively, for overnight at $4{ }^{\circ} \mathrm{C}$. After three washes with PBS, the cells were incubated with the corresponding secondary antibodies (1:500, Millipore Chemicon, Temecula, CA, USA) at RT for $1 \mathrm{~h}$, followed by three washes in the same buffer. They were then incubated with Hoechst 33342 (Sigma) at RT for 2 min. Concurrently, the negative controls were stained with conjugated secondary antibodies alone. Images were captured with Evos f1 fluorescence microscope (AMG, Millcreek, Washington, USA).

Tissues were fixed in $4 \%(\mathrm{w} / \mathrm{v})$ paraformaldehyde in $0.01 \mathrm{M}$ PBS ( $\mathrm{pH}$ 7.4), washed in PBS, dehydrated in ethanol $(70 \%, 90 \%$, and $100 \%)$ and embedded in paraffin wax. Testicular and epididymal sections $(5 \mu \mathrm{m})$ were rehydrated (xylene $5 \mathrm{~min}$; ethanol 100\%, 95\%, 70\%, $5 \mathrm{~min}$ each) and washed in distilled water prior to immunofluorescence staining.

\section{BrdU incorporation assay}

The proliferative ability of MLTC- 1 and SSCs was evaluated by BrdU incorporation assay. Briefly, cells were treated with $30 \mu \mathrm{g} / \mathrm{ml}$ BrdU (Sigma, St Louis, MO, USA) for $6 \mathrm{~h}$ before BrdU immunostaining. Then cells were fixed in 4\% paraformaldehyde (PFA) for $15 \mathrm{~min}$ at RT and washed three times ( $5 \mathrm{~min} /$ each time) with PBS (pH 7.4) containing $0.1 \%$ Triton $\mathrm{X}-100$. The cells were then washed for three times with PBS ( $\mathrm{pH}$ 7.4) alone. AntiBrdU antibody (1:100; Santa Cruz, CA, USA) dissolved in $0.1 \mathrm{M}$ PBS (pH 7.4) containing 5\% goat serum was added. After being incubated overnight at $4{ }^{\circ} \mathrm{C}$ cells were washed in PBS ( $\mathrm{pH}$ 7.4) three times and then incubated with the corresponding secondary antibody (1:500, FITC, Millipore) for $1 \mathrm{~h}$ at room temperature. After three washes with PBS, cells were visualized under an AMG fluorescent microscope and analyzed for BrdU uptake. Under the microscope magnifying 100, each sample in four random field sights were selected to conduct the quantification of the image analyses. The percentage of BrdU-positive cells was calculated as the number of BrdU-positive cells out of the total number of cells $(\times 100)$.

\section{CCK-8 assay}

For CCK-8 assay (Vazyme Biotech Co., Ltd, Nanjing PRC), MLTC-1 cells were seeded on 96-well plate. Cells were incubated in CCK- 8 solution for $1 \mathrm{~h}$ at $37^{\circ} \mathrm{C}$. The amount of formazan dye was measured by examining the absorbance at $450 \mathrm{~nm}$ with a microplate reader.

\section{RT-qPCR}

Quantitative reverse transcriptase-polymerase chain reaction (RT-qPCR) was set up in $25 \mu \mathrm{l}$ reaction mixtures containing $12.5 \mu \mathrm{l} 1 \mathrm{x}$ SYBR Premix ExTaq ${ }^{\mathrm{TM}}$ (Bioer, Hangzhou, PRC), $0.5 \mu \mathrm{l}$ sense primer, $0.5 \mu \mathrm{l}$ antisense primer, $11 \mu \mathrm{l}$ distilled water, and $0.5 \mu \mathrm{l}$ template. Reaction conditions were as follows: $95^{\circ} \mathrm{C}$ for $30 \mathrm{~s}$, followed by 45 cycles at $95^{\circ} \mathrm{C}$ for $5 \mathrm{~s}$, and $59^{\circ} \mathrm{C}$ for $20 \mathrm{~s}$. The expression levels of mRNAs were normalized to Gapdh in each well.

\section{TdT-mediated dUTP-X nicked end labeling (TUNEL assay)}

Cells were incubated for $15 \mathrm{~min}$ with proteinase $\mathrm{K}$ $(20 \mu \mathrm{g} / \mathrm{ml}$, Roche, Basel, Switzerland) at RT. Then cells were washed three times with PBS and incubated for $60 \mathrm{~min}$ at $37^{\circ} \mathrm{C}$ in a moist chamber with $50 \mu \mathrm{l}$ TUNEL mix $(5 \mu \mathrm{l}$ Terminal Deoxynucleotidyl Transferase (TdT) and $45 \mu \mathrm{l}$ fluorescein-dUTP), negative control was just added $50 \mu \mathrm{l}$ fluorescein-dUTP. After washing for three times with PBS for $5 \mathrm{~min}$ each at RT, the cells were 
incubated with Hoechst 33342 for 2 min at RT. After three PBS washes, cells were visualized under an AMG fluorescent microscope. The percentage of TUNELpositive cells was calculated as (the number of TUNELpositive cells out of the total number of cells) $\times 100$.

\section{Western blot analysis}

The tissue or cell samples were collected and lysed with lysis buffer, and then protein extractions were obtained. The protein was quantified by using a BCA Protein Assay kit (Beyotime, Shanghai, PRC). After denaturation by heating for $10 \mathrm{~min}$ at $100^{\circ} \mathrm{C}$ in $5 \%$ SDSPAGE loading buffer, the protein sample was resolved by SDS-PAGE and transferred to a PVDF membrane (61). The primary antibodies used for Western blot analysis included anti-P53 antibody (1:1000, mouse IgG, Sino Biological Inc., Beijing, PRC), anti-Bcl2 antibody (1:1000, Sino Biological Inc.), anti-Bax antibody (1:1,000, rabbit IgG, Cell Signaling Technology, Danvers, MA, USA), anti-Caspase 3 antibody (1:1000, mouse IgG, Cell Signaling Technology), anti-Chop antibody (1:1,000, mouse IgG, Sangon), anti-Grp78 antibody (1:1000, rabbit IgG Sangon), anti-CSF1 antibody (1:1000, rabbit IgG, Sangon), anti-CSF1r antibody (1:1000, mouse IgG, Sangon), and anti- $\beta$-actin antibody (1:5,000, mouse IgG2b, Cell Signaling Technology). The protein bands were detected using a Bio-Rad imaging system (Bio-Rad, Hercules, CA, USA) and quantified using Image $J$ (V1.48d).

\section{Cell cycle and apoptosis assay by flow cytometry}

Cell cycle distribution was assessed by flow cytometry after PI staining. Adherent cells were dissociated by $0.25 \%$ trypsinization and detached cells were fixed in $70 \%$ ethanol at $4{ }^{\circ} \mathrm{C}$ for $24 \mathrm{~h}$. After being washed with PBS, samples were stained with $50 \mu \mathrm{g} / \mathrm{ml}$ PI and $50 \mu \mathrm{g} / \mathrm{ml}$ RNase A at $37^{\circ} \mathrm{C}$ for $20 \mathrm{~min}$, then analyzed by flow cytometry (Beckman Altra, Beckman Coulter Inc., Brea, CA, USA). At least 5000 cells were collected per sample.

Cell apoptosis distribution was assessed after Annexin VFITC and PI staining. Cells were harvested and washed in cold PBS and cold binding buffer $\mathrm{x} 1$. They were then resuspended in cold $1 \times$ binding buffer, $1 \times 10^{6}$ cells $/ \mathrm{ml} .100$ $\mu \mathrm{l}$ cell suspension $\left(1 \times 10^{5}\right.$ cells $)$ were added to each labeled tube, $5 \mu \mathrm{l}$ Annexin V-FITC was added to appropriate tubes. Each tube was gently vortexed and incubated for $10 \mathrm{~min}$ at room temperature. $5 \mathrm{ml}$ PI solution was added then and those tubes were stabilized for $5 \mathrm{~min}$ at room temperature, protected from the light. Before the analysis, cells were washed once in PBS and resuspended with PBS. Flow cytometer was utilized to perform the measurements experiment (Beckman Altra). The fluorescence intensity was also observed under fluorescence microscope.

\section{Enzyme linked immunosorbent assay (ELISA)}

After snipping the tail tip, the blood sample was collected and plasma glucose levels were determined using the blood glucosemeter (Yicheng, Beijing, China). Animals were fasted for $12 \mathrm{~h}$ before the measurement. Mouse CSF1 level of mouse plasma was quantified using an ELISA kit (Boster, Wuhan, China) according to the instructions.

\section{Statistical analysis}

One-way analysis of variance (one-way ANOVA) was used and post-tests were conducted using Newman-Keuls multiple range test, if $P$-values are significant. Students' $t$-test was used when only two pairs of data were compared. All data are presented as mean $\pm \mathrm{SD}$, and statistical significance was expressed as follows: ${ }^{*} P<0.05$; ${ }^{* *} P<0.01$. All data are representative of at least three different experiments and were analyzed using Graphpad Prism software (La Jolla, CA, USA).

\section{Acknowledgements}

We appreciate Dr. Donadeu Xavier's excellent comments and suggestions. This study was supported by grants from the National Key Research and Development Program of China, Stem Cell and Translational Research (Grant no. 2016YFA0100203) and the National Natural Science Foundation of China (Grant no. 31572399 and 31272518).

\section{Author details}

${ }^{1}$ College of Veterinary Medicine, Shaanxi Centre of Stem Cells Engineering \& Technology, Northwest A\&F University, Yangling 712100 Shaanxi, China. ${ }^{2}$ Centre for Healthy Brain Ageing, UNSW Medicine, Randwick, NSW 2031, Australia. ${ }^{3}$ College of Animal Science \& Technology, College of Veterinary Medicine, Huazhong Agricultural University, 430070 Wuhan, China. ${ }^{4}$ College of Life Science, Northeast Agricultural University, 150036 Harbin, China. ${ }^{5}$ College of life sciences, Institute of Reproductive Sciences, Qingdao Agriculture University, 266109 Qingdao, China. ${ }^{6}$ Department of Cell Systems and Anatomy, UT Health, San Antonio TX78229-3900, USA

\section{Conflict of interest}

The authors declare that they have no conflict of interest.

\section{Publisher's note}

Springer Nature remains neutral with regard to jurisdictional claims in published maps and institutional affiliations.

Supplementary Information accompanies this paper at (https://doi.org/ 10.1038/s41419-018-0956-4).

Received: 14 June 2018 Revised: 10 August 2018 Accepted: 20 August 2018 Published online: 20 September 2018

\footnotetext{
References

1. Kilarkaje, N. \& Al-Bader, M. M. Diabetes-induced oxidative DNA damage alters p53-p21CIP1/Waf1 signaling in the rat testis. Reprod. Sci. 22, 102-112 (2015).

2. Ferreira, C. et al. Impact of metformin on male reproduction. Curr. Pharm. Des. 21, 3621-3633 (2015).

3. Jangir, R. N. \& Jain, G. C. Diabetes mellitus induced impairment of male reproductive functions: a review. Curr. Diabetes Rev. 10, 147-157 (2014).

4. Ding, G. L. et al. The effects of diabetes on male fertility and epigenetic regulation during spermatogenesis. Asian J. Androl. 17, 948-953 (2015).
} 
5. Oatley, J. M. \& Brinster, R. L. The germline stem cell niche unit in mammalian testes. Physiol. Rev. 92, 577-595 (2012).

6. Phillips, B. T., Gassei, K. \& Orwig, K. E. Spermatogonial stem cell regulation and spermatogenesis. Philos. Trans. R. Soc. Lond. B. Biol. Sci. 365, 1663-1678 (2010).

7. Kanatsu-Shinohara, M. \& Shinohara, T. Spermatogonial stem cell self-renewal and development. Annu. Rev. Cell Dev. Biol. 29, 163-187 (2013).

8. Tadokoro, Y., Yomogida, K., Ohta, H., Tohda, A. \& Nishimune, Y. Homeostatic regulation of germinal stem cell proliferation by the GDNF/FSH pathway. Mech. Dev. 113, 29-39 (2002).

9. Yomogida, K., Yagura, Y., Tadokoro, Y. \& Nishimune, Y. Dramatic expansion of germinal stem cells by ectopically expressed human glial cell line-derived neurotrophic factor in mouse Sertoli cells. Biol. Reprod. 69, 1303-1307 (2003).

10. Rato, L. et al. Testosterone deficiency induced by progressive stages of diabetes mellitus impairs glucose metabolism and favors glycogenesis in mature rat Sertoli cells. Int. J. Biochem. Cell Biol. 66, 1-10 (2015).

11. Rocha, C. S. et al. Melatonin alters the glycolytic profile of Sertoli cells: implications for male fertility. Mol. Hum. Reprod. 20, 1067-1076 (2014).

12. Chen, S. R. \& Liu, Y. X. Regulation of spermatogonial stem cell self-renewal and spermatocyte meiosis by Sertoli cell signaling. Reproduction 149, R159-R167 (2015).

13. Skurikhin, E. G. et al. Role of Sertoli and Leydig cells in the regulation of spermatogonial stem cell and development of reproductive disorders in male C57BI/6 mice with type 1 diabetes mellitus. Bull. Exp. Biol. Med. 164, 127-131 (2017).

14. Shima, Y. et al. Contribution of Leydig and Sertoli cells to testosterone production in mouse fetal testes. Mol. Endocrinol. 27, 63-73 (2013).

15. Oatley, J. M., Oatley, M. J., Avarbock, M. R., Tobias, J. W. \& Brinster, R. L. Colony stimulating factor 1 is an extrinsic stimulator of mouse spermatogonial stem cell self-renewal. Development 136, 1191-1199 (2009).

16. Harding, H. P. \& Ron, D. Endoplasmic reticulum stress and the development of diabetes: a review. Diabetes 51 (Suppl. 3), S455-S461 (2002).

17. Zhao, Y. et al. Exacerbation of diabetes-induced testicular apoptosis by zinc deficiency is most likely associated with oxidative stress, p38 MAPK activation, and p53 activation in mice. Toxicol. Lett. 200, 100-106 (2011).

18. Jiang, $X$. et al. Protective effect of FGF21 on type 1 diabetes-induced testicular apoptotic cell death probably via both mitochondrial- and endoplasmic reticulum stress-dependent pathways in the mouse model. Toxicol. Lett. 219 65-76 (2013).

19. Kim, J. H. et al. Testicular hyperthermia induces unfolded protein response signaling activation in spermatocyte. Biochem. Biophys. Res. Commun. 434, 861-866 (2013).

20. Li B., et al. Melatonin ameliorates busulfan-induced spermatogonial stem cell oxidative apoptosis in mouse testes. Antioxid Redox Signal. 28, 385-400 (2017).

21. Reiter, R. J. The melatonin rhythm: both a clock and a calendar. Experientia 49, 654-664 (1993).

22. Feng, D. et al. Pre-ischemia melatonin treatment alleviated acute neuronal injury after ischemic stroke by inhibiting ER stress-dependent autophagy via PERK and IRE1 signalings. J. Pineal Res. 62, e12395 (2017).

23. Song, J. \& Kim, O. Y. Melatonin modulates neuronal cell death induced by endoplasmic reticulum stress under insulin resistance condition. Nutrients $\mathbf{9}$ 593 (2017).

24. Lian, C. et al. Melatonin reversed tumor necrosis factor-alpha-inhibited osteogenesis of human mesenchymal stem cells by stabilizing SMAD1 protein. J. Pineal Res. 61, 317-327 (2016).

25. Niu, B. et al. Melatonin promotes goat spermatogonia stem cells (SSCs) proliferation by stimulating glial cell line-derived neurotrophic factor (GDNF) production in Sertoli cells. Oncotarget 7, 77532-77542 (2016).

26. Kim, S. H. et al. Melatonin prevents gentamicin-induced testicular toxicity and oxidative stress in rats. Andrologia 46, 1032-1040 (2014).

27. Mukherjee, A., Haldar, C. \& Vishwas, D. K. Melatonin prevents dexamethasoneinduced testicular oxidative stress and germ cell apoptosis in golden hamster, Mesocricetus auratus. Andrologia 47, 920-931 (2015).

28. Li, R. et al. The protective effects of melatonin against oxidative stress and inflammation induced by acute cadmium exposure in mice testis. Biol. Trace Elem. Res. 170, 152-164 (2016).

29. Galano A., Castaneda-Arriaga R., Perez-Gonzalez A., Tan D. X., Reiter R. J. phenolic melatonin-related compounds: their role as chemical protectors against oxidative stress. Molecules 21, e1442 (2016).

30. Reiter, R. J. et al. Melatonin as a mitochondria-targeted antioxidant: one of evolution's best ideas. Cell Mol. life Sci. CMLS 74, 3863-3881 (2017).
31. Haghi-Aminjan $\mathrm{H}_{\text {., }}$ et al. The role of melatonin on chemotherapy-induced reproductive toxicity. J. Pharm. Pharmacol. 70, 291-306 (2017).

32. Wang, W. et al. Identification of small-molecule inducers of pancreatic betacell expansion. Proc. . Natl Acad. Sci. USA 106, 1427-1432 (2009).

33. Pinhas-Hamiel, O. \& Zeitler, P. The global spread of type 2 diabetes mellitus in children and adolescents. J. Pediatr. 146, 693-700 (2005)

34. Daumler, D., Chan, P., Lo, K. C., Takefman, J. \& Zelkowitz, P. Men's knowledge of their own fertility: a population-based survey examining the awareness of factors that are associated with male infertility. Hum. Reprod. 31, 2781-2790 (2016).

35. Sisman, A. R. et al. Potential novel biomarkers for diabetic testicular damage in streptozotocin-induced diabetic rats: nerve growth factor Beta and vascular endothelial growth factor. Dis. Markers 2014, 108106 (2014).

36. La, V. S., Condorelli, R., Vicari, E., D'Agata, R. \& Calogero, A. E. Diabetes mellitus and sperm parameters. J. Androl. 33, 145-153 (2012).

37. Liu, X., Jin, X., Su, R. \& Li, Z. The reproductive toxicology of male SD rats after PM2.5 exposure mediated by the stimulation of endoplasmic reticulum stress. Chemosphere 189, 547-555 (2017).

38. Lenna, S., Han, R. \& Trojanowska, M. Endoplasmic reticulum stress and endothelial dysfunction. IUBMB Life 66, 530-537 (2014).

39. Park, J. H. et al. Melatonin prevents pancreatic beta-cell loss due to glucotoxicity: the relationship between oxidative stress and endoplasmic reticulum stress. J. Pineal Res. 56, 143-153 (2014).

40. Eizirik, D. L., Cardozo, A. K. \& Cnop, M. The role for endoplasmic reticulum stress in diabetes mellitus. Endocr. Rev. 29, 42-61 (2008).

41. Scheuner, D. \& Kaufman, R. J. The unfolded protein response: a pathway that links insulin demand with beta-cell failure and diabetes. Endocr. Rev. 29, 317-333 (2008).

42. Yin, J. J. et al. The role of autophagy in endoplasmic reticulum stress-induced pancreatic beta cell death. Autophagy 8, 158-164 (2012).

43. Oyadomari, S., Araki, E. \& Mori, M. Endoplasmic reticulum stress-mediated apoptosis in pancreatic beta-cells. Apoptosis Int. J. Program. Cell death 7, 335-345 (2002).

44. Shepherd, P. R. \& Kahn, B. B. Glucose transporters and insulin action-implications for insulin resistance and diabetes mellitus. N. Engl. J. Med. 341, 248-257 (1999).

45. Chow, C. Y., Avila, F. W., Clark, A. G. \& Wolfner, M. F. Induction of excessive endoplasmic reticulum stress in the Drosophila male accessory gland results in infertility. PLOS ONE 10, e0119386 (2015).

46. Rato, L., Alves, M. G., Dias, T. R., Cavaco, J. E. \& Oliveira, P. F. Testicular metabolic reprogramming in neonatal streptozotocin-induced type 2 diabetic rats impairs glycolytic flux and promotes glycogen synthesis. J. Diabetes Res. 2015, 973142 (2015).

47. Bonnefont-Rousselot, D., Collin, F., Jore, D. \& Gardes-Albert, M. Reaction mechanism of melatonin oxidation by reactive oxygen species in vitro. J. Pineal Res. 50, 328-335 (2011).

48. Galano, A., Tan, D. X. \& Reiter, R. J. Melatonin as a natural ally against oxidative stress: a physicochemical examination. J. Pineal Res. 51, 1-16 (2011).

49. Galano, A., Tan, D. X. \& Reiter, R. J. On the free radical scavenging activities of melatonin's metabolites, AFMK and AMK. J. Pineal Res. 54, 245-257 (2013).

50. Reiter, R. J., Tan, D. X. \& Galano, A. Melatonin: exceeding expectations. Physiol. 29, 325-333 (2014).

51. Reiter, R. J. et al. Melatonin as an antioxidant: under promises but over delivers. J. Pineal Res. 61, 253-278 (2016).

52. Cohen Engler, A., Hadash, A., Shehadeh, N. \& Pillar, G. Breastfeeding may improve nocturnal sleep and reduce infantile colic: potential role of breast milk melatonin. Eur. J. Pediatr. 171, 729-732 (2012).

53. Carpentieri, A., Diaz de Barboza, G., Areco, V., Peralta Lopez, M. \& Tolosa de Talamoni, N. New perspectives in melatonin uses. Pharmacol. Res. 65, 437-444 (2012).

54. Mooradian, A. D. \& Haas, M. J. Glucose-induced endoplasmic reticulum stress is independent of oxidative stress: a mechanistic explanation for the failure of antioxidant therapy in diabetes. Free Radic. Biol. Med. 50, 1140-1143 (2011).

55. Sheikh-Ali, M., Sultan, S., Alamir, A. R., Haas, M. J. \& Mooradian, A. D. Effects of antioxidants on glucose-induced oxidative stress and endoplasmic reticulum stress in endothelial cells. Diabetes Res. Clin. Pract. 87, 161-166 (2010).

56. Fernandez, A., Ordonez, R., Reiter, R. J., Gonzalez-Gallego, J. \& Mauriz, J. L. Melatonin and endoplasmic reticulum stress: relation to autophagy and apoptosis. J. Pineal Res. 59, 292-307 (2015). 
57. Yoo, Y. M. Melatonin-mediated insulin synthesis during endoplasmic reticulum stress involves HuD expression in rat insulinoma INS-1E cells. J. Pineal Res. 55 207-220 (2013).

58. Wang, $\mathrm{H}$. et al. Melatonin alleviates lipopolysaccharide-induced placenta cellular stress response in mice. J. Pineal Res. 50, 418-426 (2011).

59. Ji, Y. L. et al. Melatonin alleviates cadmium-induced cellular stress and germ cell apoptosis in testes. J. Pineal Res. 52, 71-79 (2012).

60. Chen, Y. et al. Melatonin induces anti-inflammatory effects to play a protective role via endoplasmic reticulum stress in acute pancreatitis. Cell. Physiol. Biochem. Int. J. Exp. Cell Physiol. Biochem. Pharmacol. 40, 1094-1104 (2016).

61. DeFalco, T. et al. Macrophages contribute to the spermatogonial niche in the adult testis. Cell Rep. 12, 1107-1119 (2015).

62. Li X. Y., et al. Regulation of blood-testis barrier assembly in vivo by germ cells. FASEB J. 32, 1653-1664 (2017).

63. Yu K., Deng S. L., Sun T. C., Li Y. Y., Liu Y. X. Melatonin regulates the synthesis of steroid hormones on male reproduction: a review. Molecules 23, e447 (2018).
64. Li, Y., Guo, Y., Tang, J., Jiang, J. \& Chen, Z. New insights into the roles of CHOPinduced apoptosis in ER stress. Acta Biochim. Biophys. Sin. 46, 629-640 (2014).

65. Bishayi, B., Adhikary, R., Nandi, A. \& Sultana, S. Beneficial effects of exogenous melatonin in acute Staphylococcus aureus and Escherichia coli infectioninduced inflammation and associated behavioral response in mice after exposure to short photoperiod. Inflammation 39, 2072-2093 (2016).

66. Sanchez D. I., et al. Melatonin modulates dysregulated circadian clocks in mice with diethylnitrosamine-induced hepatocellular carcinoma. J. Pineal Res. 65, e12506 (2018).

67. Li, B. et al. Melatonin ameliorates busulfan-induced spermatogonial stem cell oxidative apoptosis in mouse testes. Antioxid. Redox Signal. 28, 385-400 (2018).

68. Hofmann, M. C., Braydich-Stolle, L., Dettin, L., Johnson, E. \& Dym, M. Immortalization of mouse germ line stem cells. Stem Cells 23, 200-210 (2005).

69. Hofmann, M. C., Narisawa, S., Hess, R. A. \& Millan, J. L. Immortalization of germ cells and somatic testicular cells using the SV40 large T antigen. Exp. Cell Res. 201, 417-435 (1992). 